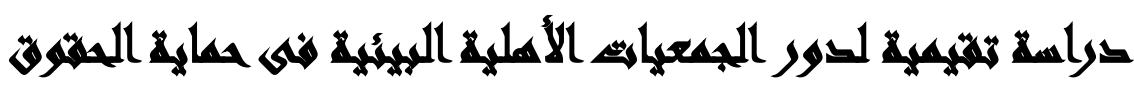

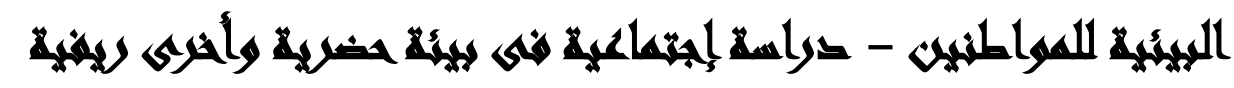

\section{[Ir]}

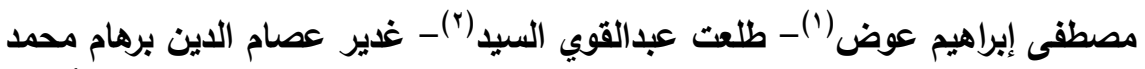

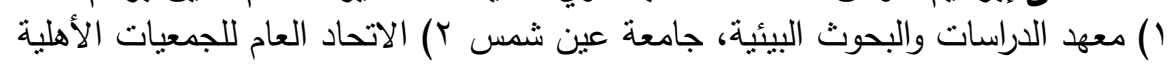

\section{المستخلص المئري}

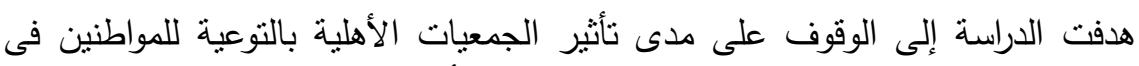

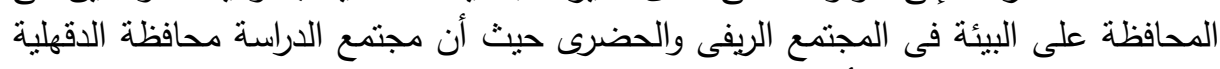

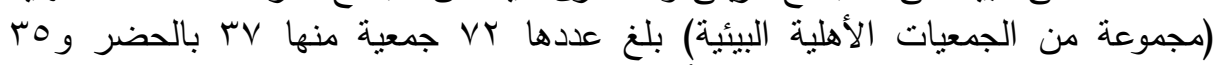

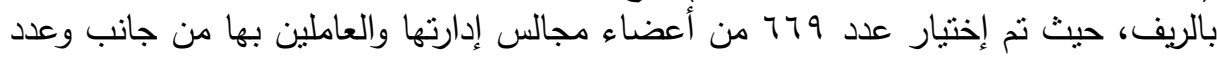

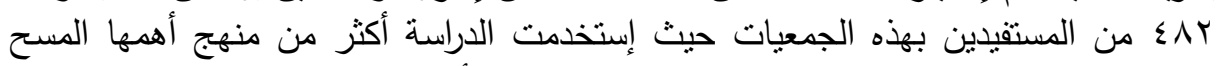

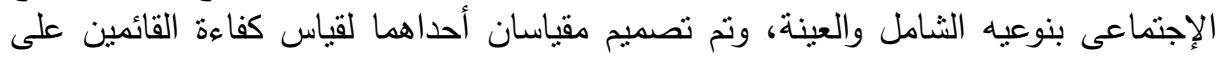

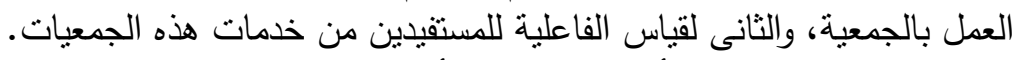

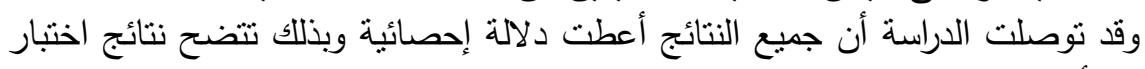

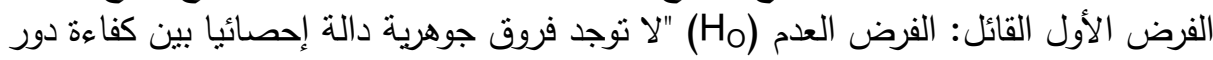

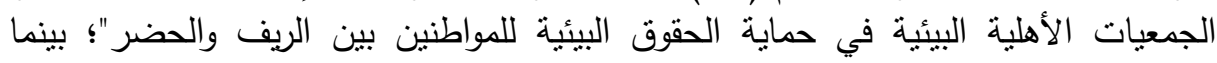

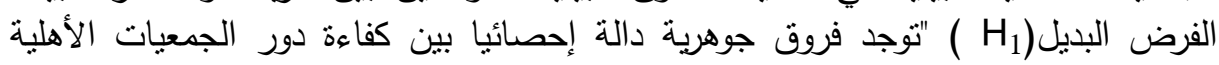

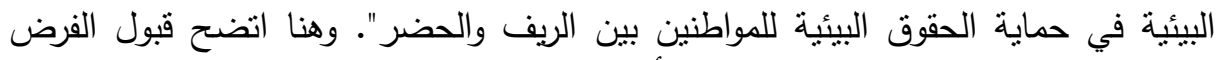

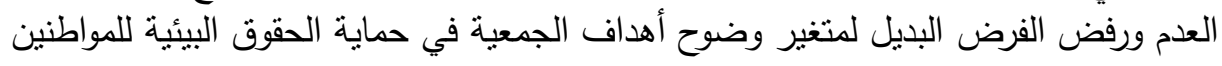
في كل من الريف والحضر .

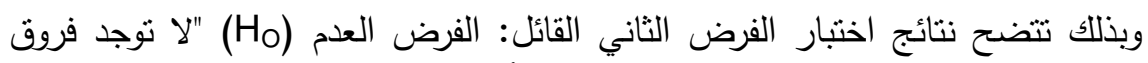

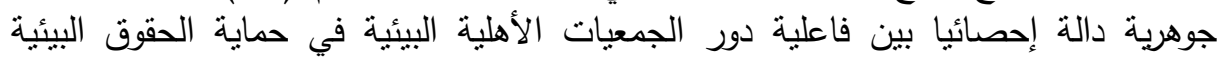

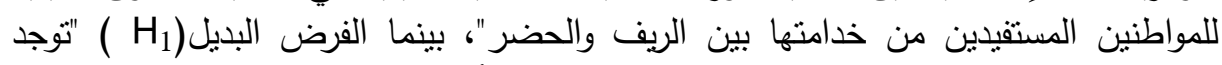
فروق جوهرية دالة إحصائيا بين فاعلية دور الجمعيات الأهلية البيئية في حماية الحين الحقوق البين البيائية

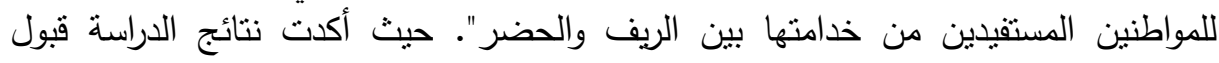
الفرض البديل ورفض الفرضن الفرن العدم.

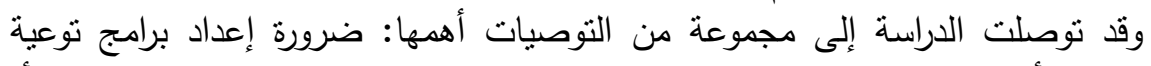

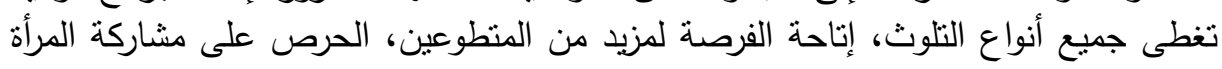

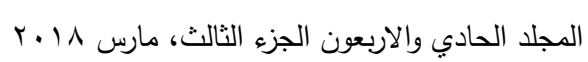


مجلة العلوم البيئية

معهد الدراسات والبحوث البيئية - جامعة عين شمس ليه

فى الأنشطة البيئية، الإستعانة بمتخصصين فى مجال حماية البيئة، شمول مناهج التربية والتعليم على مادة أساسية للبيئة.

\section{ranadl}

تعد الجمعيات الإهلية إحدى مكونات المجتمع المدنى، وهذه الجمعيات التى تتنشر فى

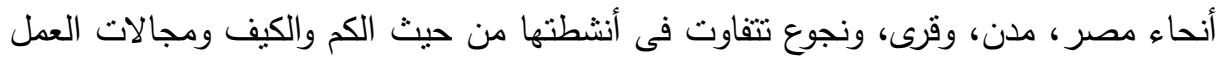

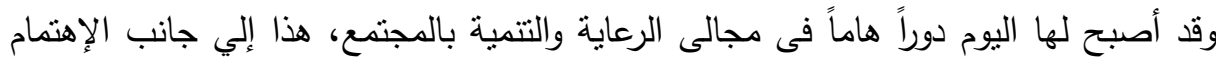

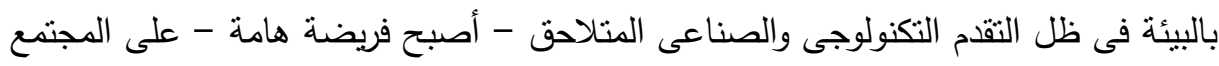

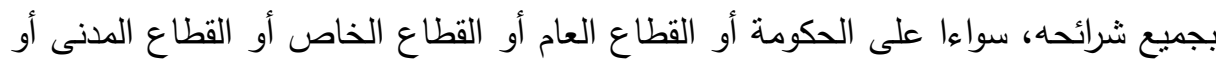

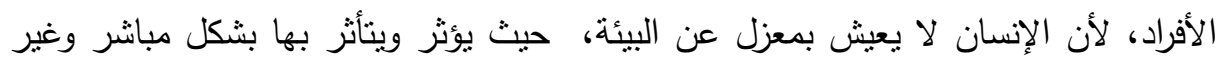

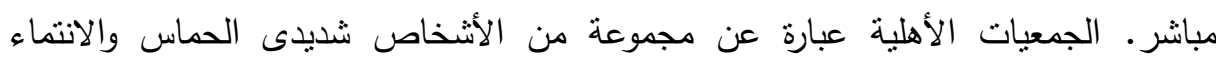

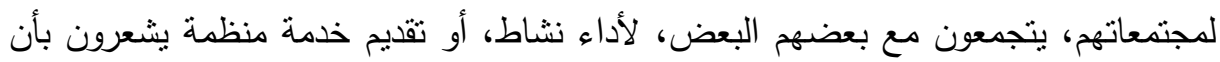

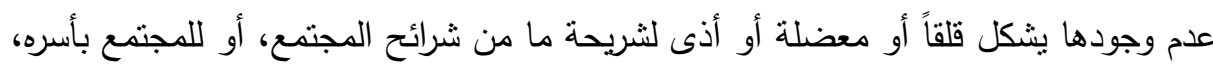
معتمدين فى ذلك على مجهوداتهم، ومجهودات غيرهم من المهتمين الذين يتطوعون لإسنادهم

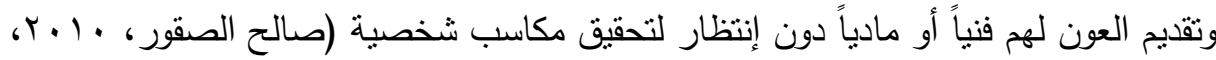

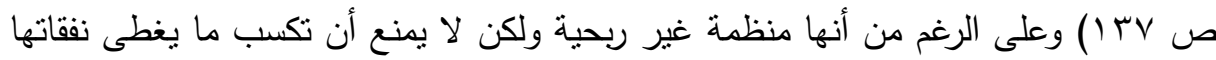

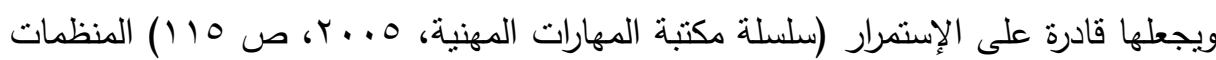

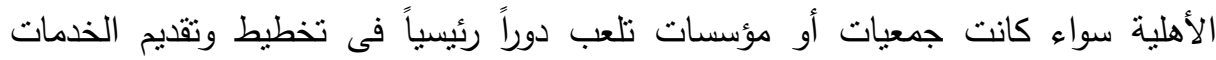
الإجتماعبة فى مصر حيث تعتبر هذه الهيئات شريكة للمنظمات الحكومية فى تحقيق أهدافها

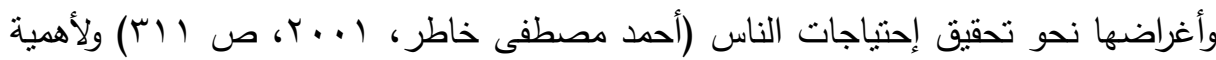
تقييم دور الجمعيات الأهلية فى حماية الحقوق البيئية للمواطنين، تدور هذه الدراسة النى بين أيدينا حيث نم تطبيقها ميدانياً فى بيئة حضرية وأخرى ريفية بمحافظة الدقهلية من خلال

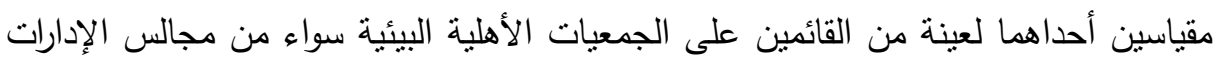
أو من العاملين بالجمعية. بينما الأخر للمبحوثين من المستقيدين من خدمات الجمعيات الأهلية البيئية. 


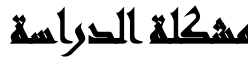

أصبح تلوث البيئة مشكلة تؤرق جميع المجتمعات بصفة عامة سواءا الريفية أو الحضرية ويعثبر ذللك ضريبة التكنولوجيا الحديثة التى تنزك الكثير من النفايات كتلوث الهواء، وتلوث

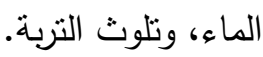
ومن مشاهدات الباحثة وملاحظاتها بالحياة اليومية بأن بعض الأفراد يقومون بالتأثثر

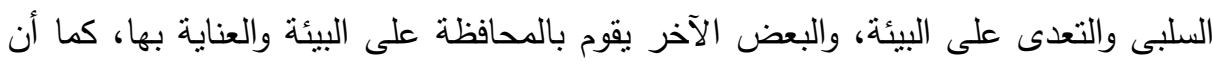

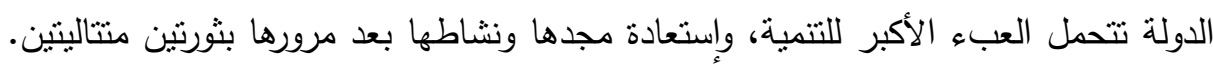

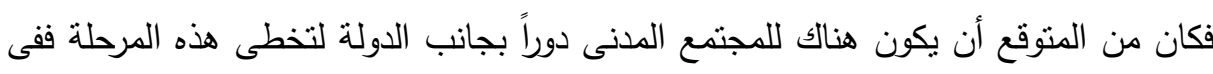

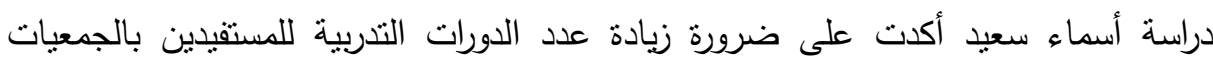

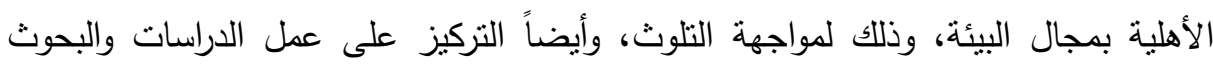

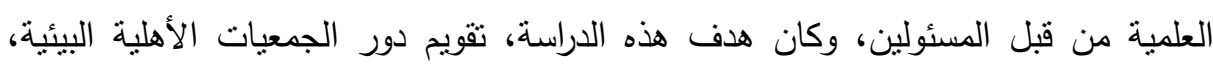

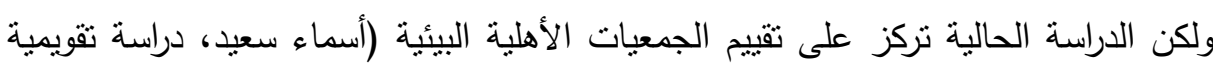

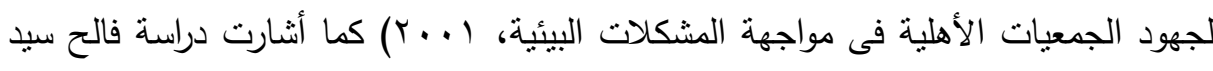

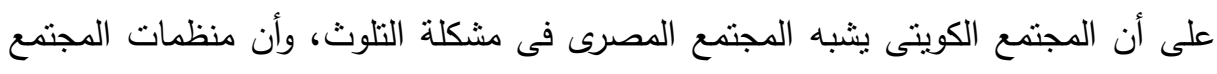

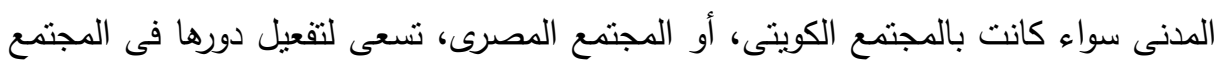

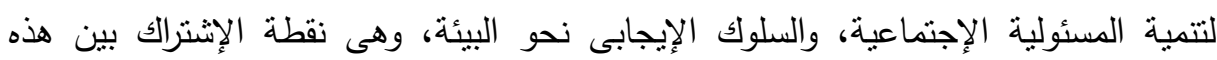

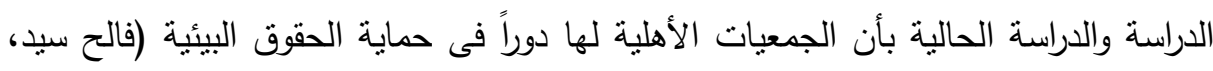

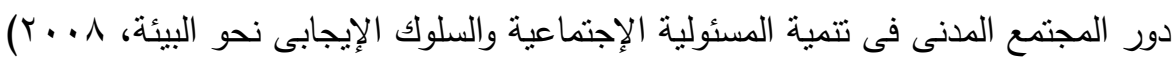
ومن هنا جاعت فكرة الدراسة، لدراسة دور الجمعيات الأهلية فى حماية الحقوق البئئية.

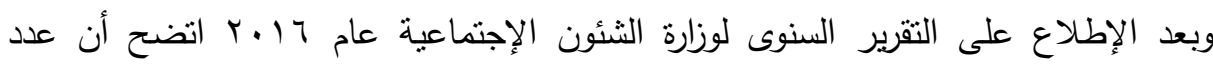

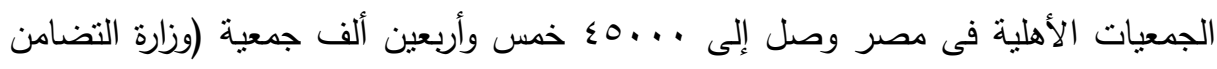

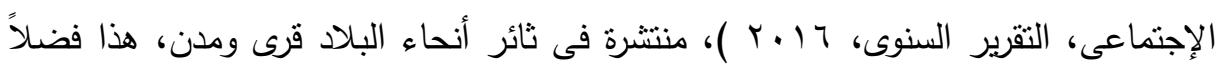

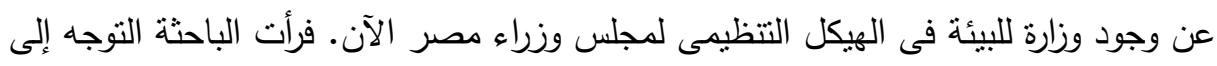

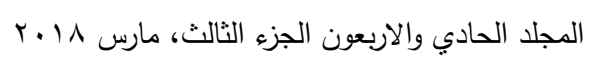


مجلة العلوم البيئية

معهد الدراسات والبحوث البيئية - جامعة عين شمس لئ

الجمعيات الأهلية لمعرفة دورها فى مجال البيئة، سواء لنظافة البيئة أو توعية المواطنين

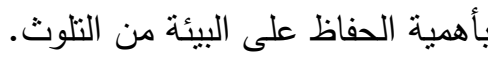

\section{أهمية التصواسم}

تعد البيئة النظيفة إحدى مؤشرات المجتمعات المتقدمة لأن نظافة البيئة من شأنها أن تنشئ إنساناً صحيح البدن والنفس والعقل. ولكي يتم ذلك فإن أهمية الحفاظ علي البيئة تكون من جانبين: أولاً: الاهمية النظرية: وتتمنل في توفير المادة العلمية الصحيحة والتي يمكن الرجوع إليها

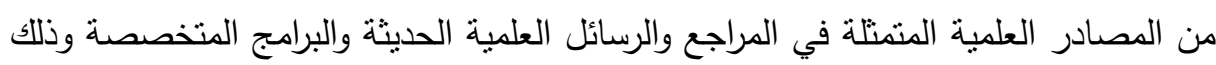
بهدف تعريف المواطن بحقوقه البيئية. ثانياً: الأهمية المجتمعية: وتتمنل في تضافر جهود المجتمع بأفراده وايمانه بأهمية الحفاظ علي البيئة ولا تقتصر علي البرامج النظرية بل الخطط العملية الصحيحة والمبنية علي علي إيمان وقناعة جميع أفراد المجتمع سواء بالحكومة أو القطاع الخاص أو القطاع الأهلي علي لئه السواء. والجمعيات الأهلية لها دور كبير إلى جانب الحكومة فى الحفاظ على البيئة فى المجتمع

$$
\text { الحضرى والمجتمع الريفى على السواء. }
$$

كما تحاول هذه الدراسة بحث دور المواطنين بجانب الجمعيات الأهلية فى الحفاظ على البيئة ومدى إدراك العلاقة بين المواطنين والجمعيات الأهلية فى هذا المجال من خلال نشاط الجمعيات فى المجتمع المحلى سواء فى الريف أو الحضر .

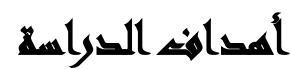

هدفت الدراسة إلى الوقوف على مدى نأثير الجمعيات الأهلية بالتوعية للمواطنين فى المحافظة على البيئة فى المجتمع الريفى والحضرى. الهدف الرئيسى: تقييم دور الجمعيات الأهلية البيئية فى حماية الحقوق البيئية للمواطنين بالمجتمع الحضرى والمجتمع الريفى من خلال المجتمع المحلى الموجود به هذه الجمعيات. 274

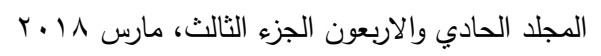




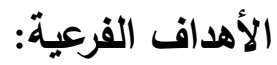

ا. التعرف على كفاءة الأنشطة والمشروعات بالجمعيات العاملة بمجال البيئة من وجهة نظر المستقيدين.

r. التعرف على فاعلية الأنشطة والمشروعات بالجمعيات الأهلية البيئية فى حماية الحقوق البيئية للمواطنين من وجهة نظر المسئولين.

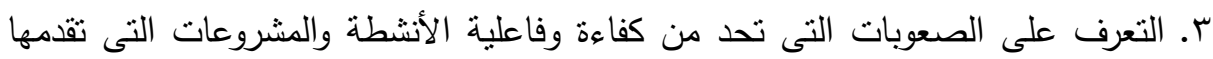

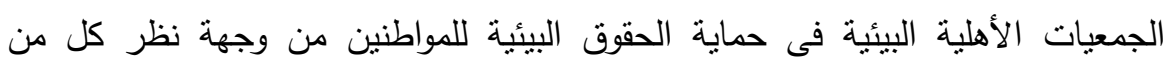
المسئولين والمستفيدين ع. المقارنة بين فاعلية الجمعيات المرتمة بالبيئة فى الريف والحضر .

\section{هغونه التراسما}

إذا كان الفرض يعبر عن توقع بوجود علاقة بين متغيرين أو أكثر وقد تؤكد نتائج البحث

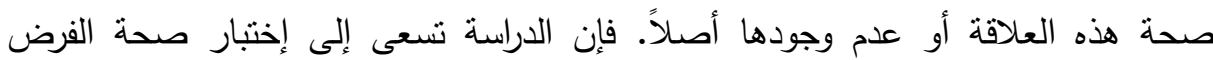
الرئيسي التالي: - n الفرض الرئيسي الأول:

الفرض العدم (Ho) "لا نوجد فروق جوهرية دالة إحصائيا بين كفاءة دور الجمعيات الأهلية البيئية في حماية الحقوق البيئية للمواطنين بين الريف والحضر "له

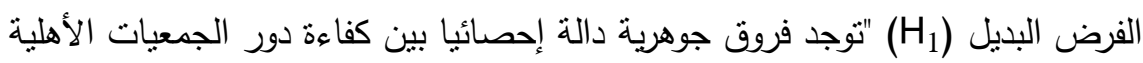
البيئية في حماية الحقوق البيئية للمواطنين بين الريف والحضر". ويمكن اختبار صحة هذه الفرض من خلال الفروض التالية:1-توجد فروق جوهرية دالة إحصائيا بين وضوح أهداف الجمعية في حماية الحقوق البيئية

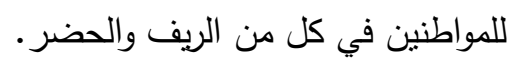
r-توجد فروق جوهرية دالة إحصائيا بين مدى وقوف المشروعات التي تقدمها الجمعية في حماية الحقوق البيئية للمواطنين في كل من الريف والحضر . 
r-توجد فروق جوهرية دالة إحصائيا بين مدى قدرات الجمعية المادية والبشرية لتحقيق

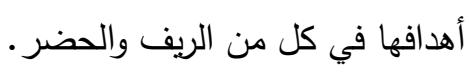

ع-توجد فروق جوهرية دالة إحصائيا بين مدى تغطية الجمعية لاحتياجات المجتمع البيئية في كل من الريف والحضر. الفرض الرئيسي الثاني:

الفرض العدم (Ho ) "لا توجد فروق جوهرية دالة إحصائيا بين فاعلية دور الجمعيات

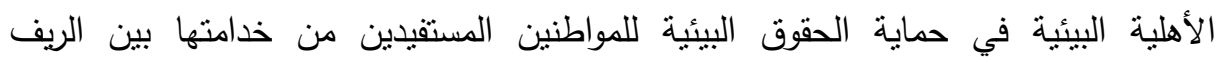
والحضر".

الفرض البديل (H) "توجد فروق جوهرية دالة إحصائيا بين فاعلية دور الجمعيات

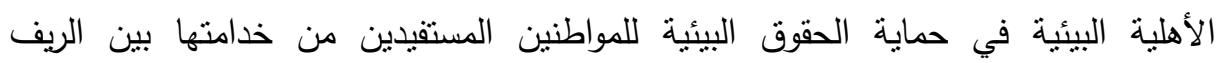

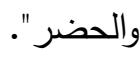
ويمكن اختبار صحة هذه الفرض من خلال الفروض التالية:1-توجد فروق جوهرية دالة إحصائيا بين وضوح أهداف أنشطة ومشروعات الجمعية بالنية بالنسبة

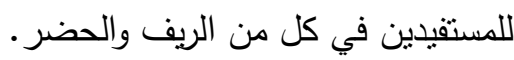
r-توجد فروق جوهرية دالة إحصائيا بين الوقوف على المشروعات التي تقدمها الجمعية

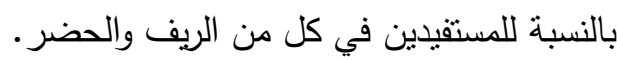
r-توجد فروق جوهرية دالة إحصائيا بين الوقوف عنى ملى مدى تغطية الأنشطة لاحتياجات المستفيدين في كل من الريف والحضر .

ع-توجد فروق جوهرية دالة إحصائيا بين الوقوف على مدى تغطية المشروعات لحاجة البيئية في كل من الريف والحضر • 


\section{مهاسهيه التراسمة}

الجمعيات الأهلية البيئية، البيئة، الحقوق البيئية.

الجمعيات الأهلية: هى تجمعات إنسانية تبنى بغرض تحقيق أهداف معينة (آيات شعراوى،

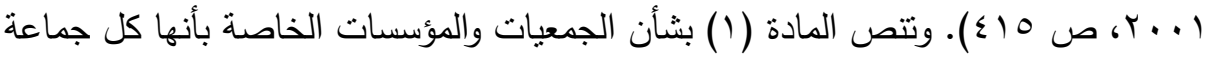
ذات نتظيم مستمر لمدة معينة أو غير معينة كانت من أثنخاص عاديين أو إعتباريين لا يقل عددهم عن عشرة أشخاص ليس بغرض الحصول على ربح (قانون الجمعيات والمؤسسات

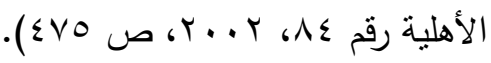

الجمعيات الأهلية البيئية: تعريف الجمعيات الأهلية العاملة فى مجال البيئة: هى وحدات أُنشئت من أبناء المجتمع المحلى لا تهدف للربح وتشعى إلى تثمية الموارد البشرية والبيئية

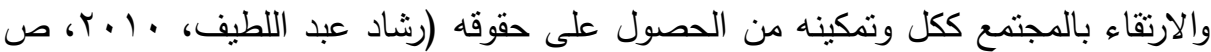

البيئة: البيئة هى المحيط الحيوى الذى بشمل الكائنات الحية، والموارد الحيوية وما بحيط به

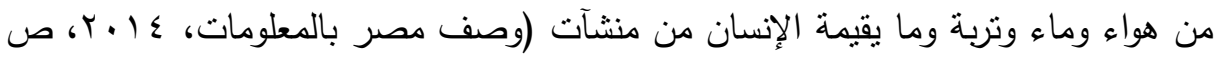

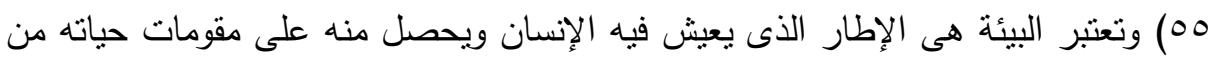

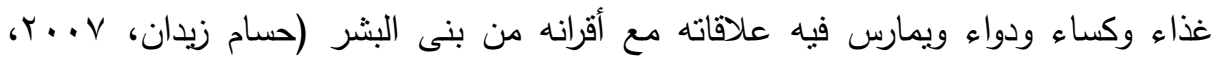

الحقوق البيئية: الحقوق البيئية هى الحقوق التى ينبغى أن يحصل عليها كل مواطن فى بيئته من هواء نظيف وماء نظيف ومسكن صحى وبيئة يمكن العيش فيها (عبد المعبود عبد

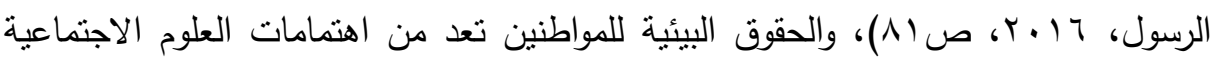
ومنها الخدمة الإجتماعية، فهى تعمل على تعريف المواطن بحقوقه البيئية، سواء كانت اجتماعية، واقتصادية، وكذلك قيامه بواجباته نحو الحفاظ على العناصر الطبيعية الموجودة

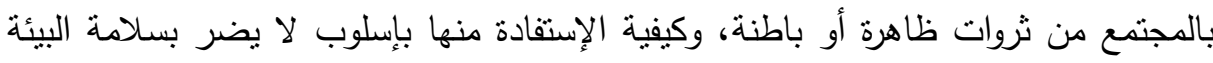

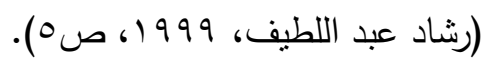




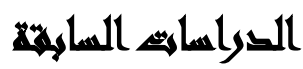

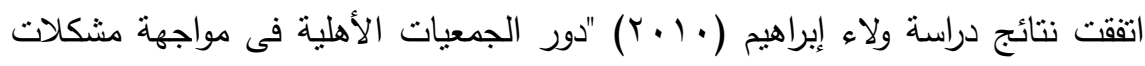
التلوث البيئى" مع الدراسة الحالية فى التأكيد على أهية دور الجمعيات الأهلية فى المحافظة دوانية

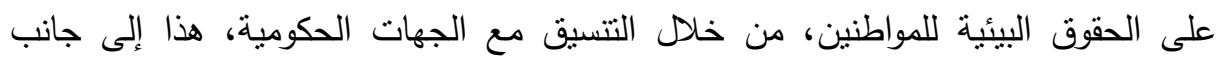

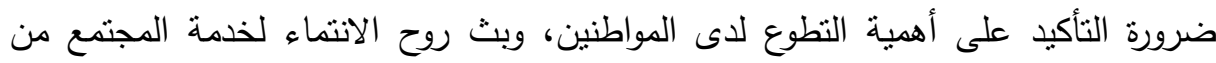

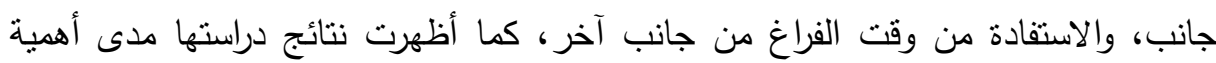
وفائدة الندوات والمحاضرات التى عقدت للمواطنين واستجابتهم للمشاركة فى الأنشطة البيئية.

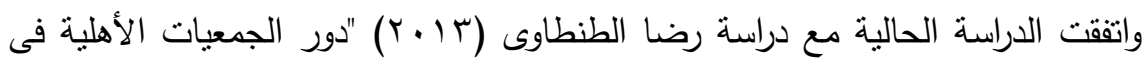

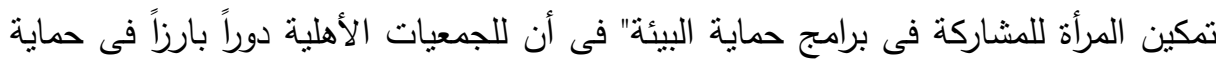

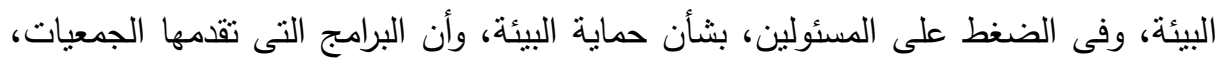

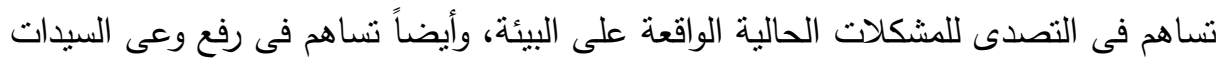

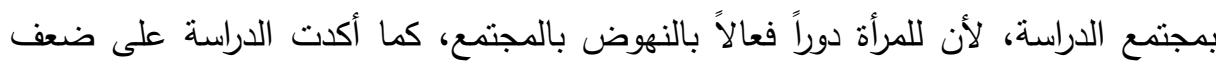
الدور الذى تقوم به المؤسسات الحكومية فى مساندة الجمعيات الأهلية العاملة بمجال البيئة، وضعف التتسيق بين الجمعيات، مما يؤدى إلى عدم تكامل الأدوار بين الجمعيات الأهلية بمجال البيئة، لأن حماية البيئة مسئولية مشتركة على المجتمع ككل، ولا تقوم على الجهود الفردية. هذا من جانب ومن جانب آخر اتفقت الدراسة الحالية مع دراسة محمود عبد الحميد

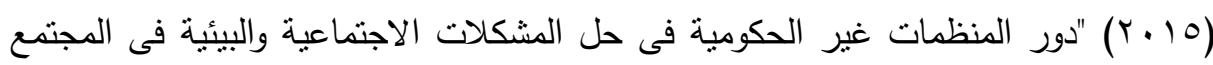

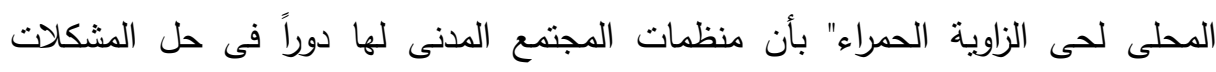
الإجتماعية والبيئية فى المجتمع المحلي، ولكن نتائج دراسته أكدت على عدم إقبال المواطنين

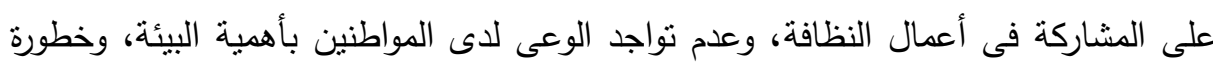

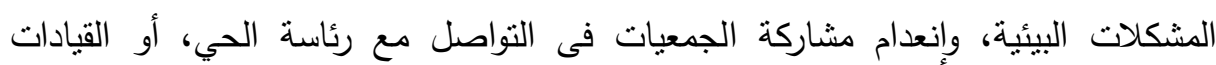

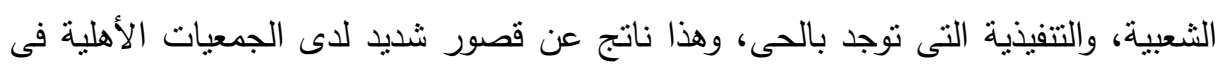
القيام بدورها. 


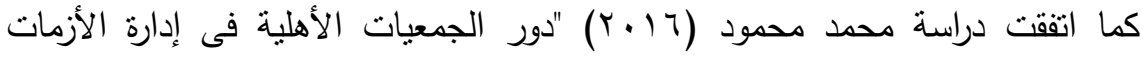

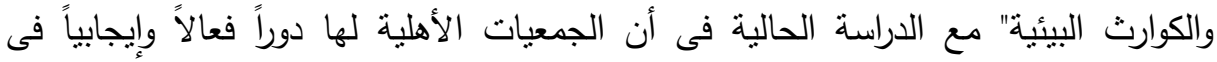
مواجهة الأزمات والكوارث البيئية، وهذا يساعد فى الحد من المخاطر والكوارث البيئية، من خلال التوعية، كالمؤتمرات، واللقاءات التليفزيونية، والبرامج التدريبية، وورش العمل، والمطبوعات، وكل هذا لإعداد الأفراد لمواجهة المخاطر البيئية، ولمعرفة حقوقهم البيئية.

\section{الإطالر المظظهى}

مدخل الاراسة: تلاحظ فى الآونة الأخيرة عجز الحكومة بأجهزتها المختلفة فى الحفاظ على البيئة من التلوث، سواءا البيئة الحضرية المنتشرة فيها المصانع والمكنظة بعدد السكان وازدحام الثوارع والطرق بالمواصلات والتى تسبب التلوث الثديد، أو البيئة الريفية من جراء الإسراف فى استخدام المبيدات الحشرية فى الزراعة، والكيماويات، والصرف الزراعى فى مجارى المياه العذبة بالإضافة إلى عدم وجود التوعية اللازمة والمطلوبة لأهالى الريف للحفاظ على البيئة. كل ذلك أدى إلى ضرورة أن تُدلى الجمعيات الأهلية بدلائها فى مجال التوعية بأهمية البيئة، وخطورة إهمالها، على الإنسان، على المستويين القريب والبعيد على السواء، فمصر التى يبلغ تعداد سكانها ؛ ـ ا مليون نسمة فيها عدد من الجمعيات أكثر من 0 ـ ألف جمعية.

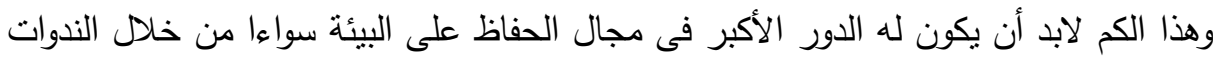
والمناقثات، والبرامج التدريبية، أو حملات النظافة، كل حسب نطاقها الجغرافى الذى تعمل به.

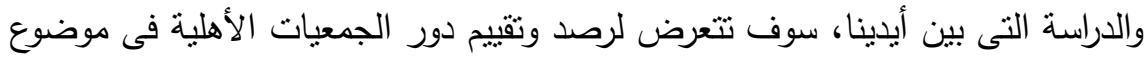

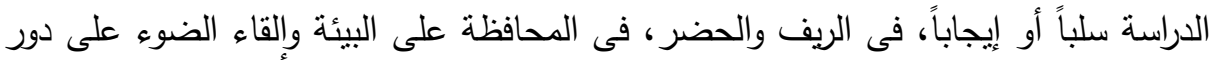
المواطن، وإبراز حقوقه وواجباته البيئية فى المجتمع الذى يعيش فيه. دوافع إختيار مشكلة الاراسة: نم إختيار مشكلة الدراسة من مشاهدات الباحثة وملاحظاتها بالحياة اليومية بأن بعض الأفراد يقومون بالتأثير السلبى والتعدى على البيئة،

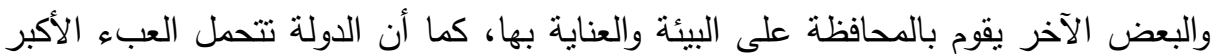

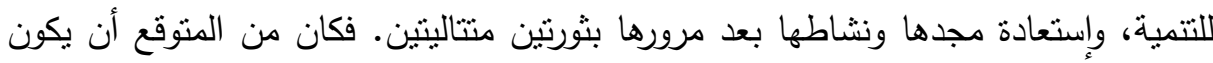
هناك للمجتمع المدنى دوراً بجانب الدولة لتخطى هذه المرحلة. ومن هناء جاءت فكرة الدراسة،

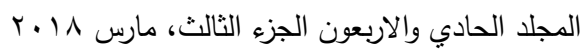


لدراسة دور الجمعيات الأهلية فى حماية الحقوق البيئية. وبعد الإطلاع على التقرير السنوى

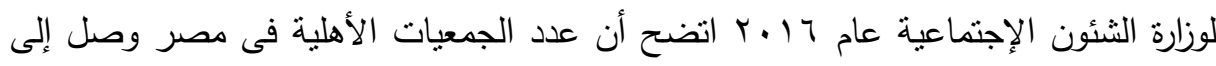

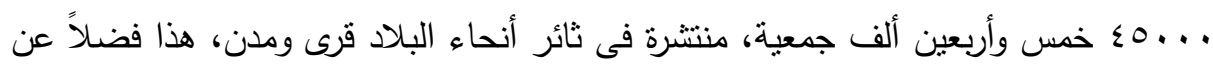

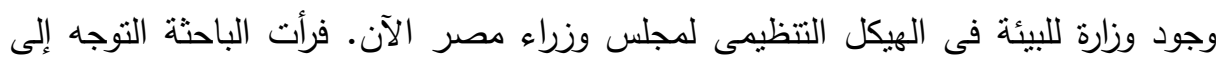

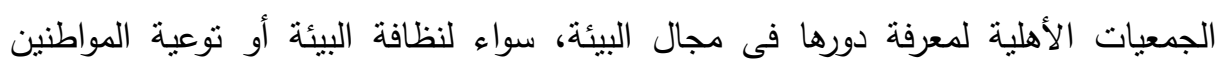

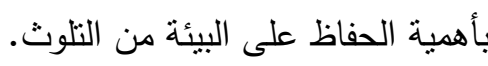

\section{المنطلقات النظرية للاراسة:}

النظرية الإجتماعية هي قاعدة عامة بسترشد بها الباحث الإجتماعي للوصول إلي تفسير وفهم

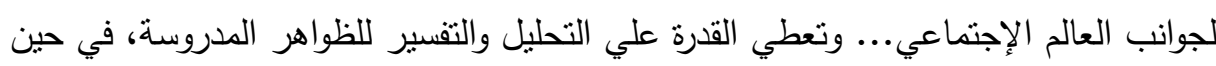
أشار قاموس الخدمة الإجتماعية إلي أبرز مكونات النظرية حين عرفها بأنها مجموعة من

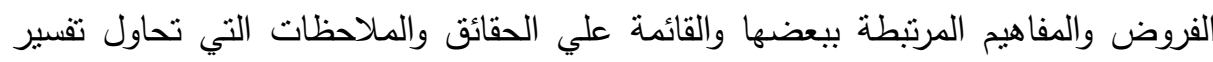
ظاهرة معينة. تعريف عبدالباسط عبدالمعطي للنظرية: نسق تصوري تمت صياغته في ضي ضوك

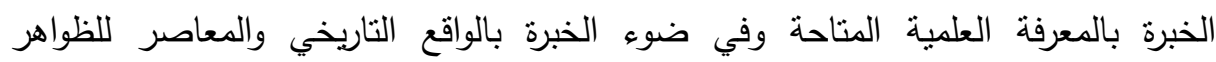
ومكوناتها وحركتها وعلاقات هذه الظواهر ببعضها ومستقبل هذه العلاقات. وتلعب النظرية دوراً هاماً في العلوم الإجتماعية فهي تساعد علي فهم الواقع الإجتماعي المعقد ومحاولة التتبؤ

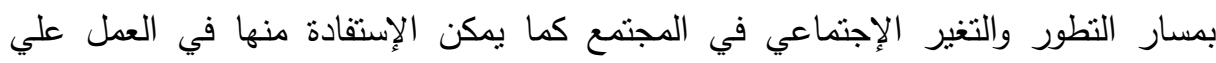

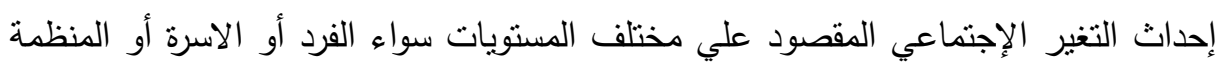
أو النسق الإجتماعي أو المجتمع. وقد استعانت الباحثة بكل من نظرية الدور الإجتماعى والنظرية الأيكولوجية وسيتم

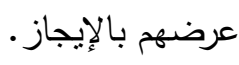
نظرية الدور الإجتماعى: ويتلخص مضمون نظرية الدور في أن كل فرد يشغل مركزاً إجتماعياً معيناً في السلم الإجتماعي هذا المركز يحتم عليه مجموعة من الحقائق والإلتزامات

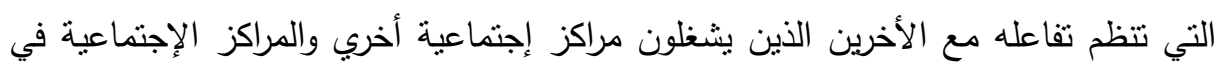

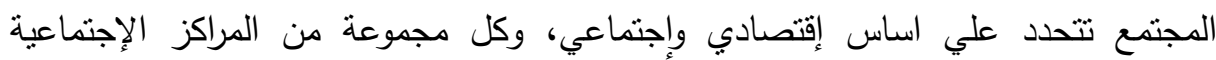

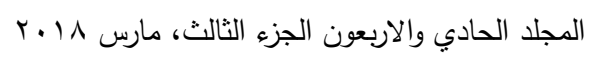


المتقاربة في المستوي بينها علاقة أفقية. أما المراكز الإجتماعية المختلفة، فإن العلاقة بينها رأسية ، وكل مركز إجتماعي يرتبط به ايضاً مجموعة من المعايير أو التوقعات التي تحدد التهاعيه الأنماط السلوكية التي يتبعها شاغل المركز نحو أنخاص أخرين يشغلون مراكز إجتماعية

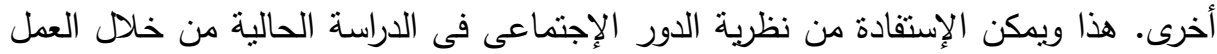
بالجمعيات الأهلية، حيث تزخر هذه الجمعيات بالعديد من العاملين بها سواء كانوا متطوعين،

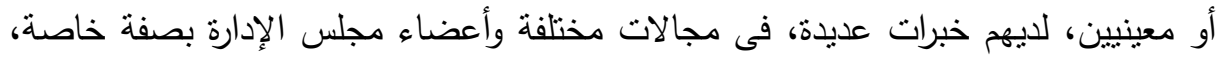

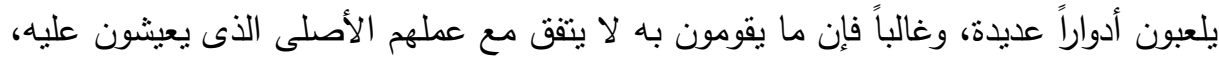

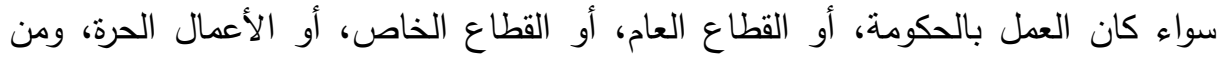

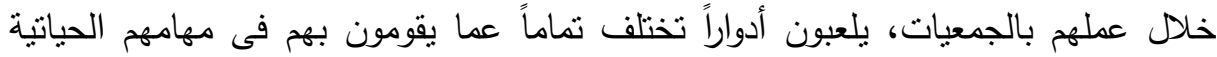

اليومية. وليس ذلك فحسب بل الأعضاء أنفسهم بالجمعية كل يلعب دوراً يختلف عن الآخر . النظرية الأيكولوجية: لكى تتجح الجمعية فى عملها لابد من العمل من خلال خطة موضوعية

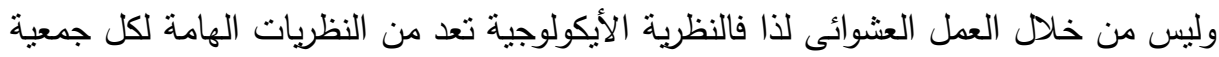
ترغب فى العمل الموضوعى لخدمة المجتمع الذى تخدمه وذللك ناشئ من طبيعة العمل بالجمعيات الأهلية فهى تخدم البشر وبالتالى لابد من التحامها مع أفراد المجتمع لزيادة التقة ومعرفة الاحتياجات المجتمعية بالبيئة المحيطة بها.

\section{الإجباءايت المنمجيهي}

نوع الدراسة: تعد هذه الدراسة من الدراسات الوصفية التحليلية لكونها أنسب أنواع الدراسات ملائمة لطبيعة موضوع الدراسة. منهج الدراسة: استخدمت الدراسة منهج المسح الإجتماعى بنوعية الثامل وبالعينة والمنهج الوثائقى.

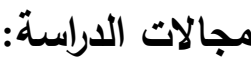

المجال المكاني: قام فريق البحث باختيار المجال المكاني للاراسة وهو بمدن وقرى بمحافظة الدقهلية حضر وريف. 
المجال البشري: تمثل المجال البشري للاراسة الحالية على النحو التالي:-

• حصر شامل لأعضاء مجالس إدارات الجمعيات الأهلية المختارة.

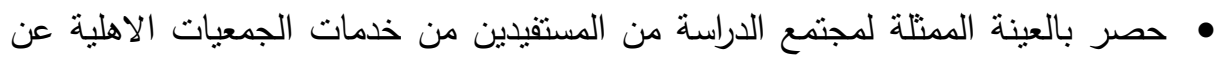

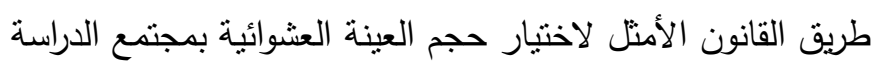

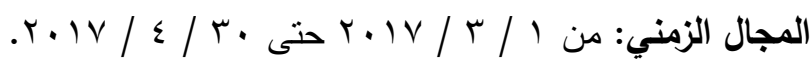
عينة الدراسة: • عدد (rTr) عضو مجلس إدارة و(91 (1)) مستقيد من إجمالى عدد (rV) جمعية أهلية

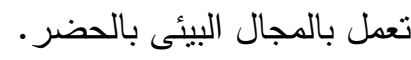
• عدد (Y.V) عضو مجلس إدارة و(Y^乏) مستقيد من إجمالى عدد (Y0) جمعية أهلية تعمل بالمجال البيئى بالريف.

أدوات جمع البيانات: اعتمدت الدراسة على مقياسى (مقياس الكفاءة - مقياس الفاعلية): الأول لقياس كفاءة دور الجمعيات الأهلية العاملة في مجال البيئة بالتطبيق على أعضاء مجالس إدارات الجمعيات الأهلية تشتمل عباراته على 0؛ عبارة وذللك لمعرفة مدى قدرات الجمعيات فى تحقيق أهدافها. والثاني لقياس فاعلية دور الجمعيات الأهلية العاملة في مجال البيئة بالتطبيق على المستقيدين

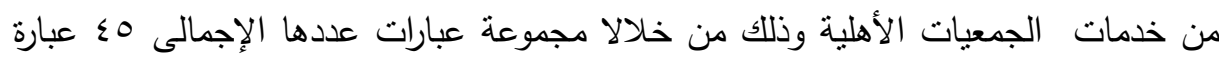
لمعرفة مدى قدرة الخدمات المقدمة لإشباع إحتياجات المستفيدين.

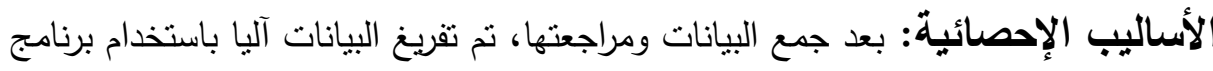

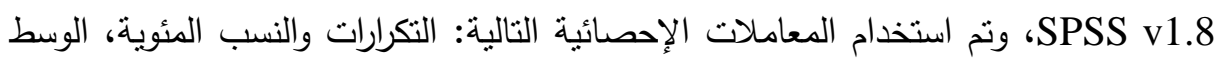
الحسابي، الانحراف المعياري. صدق وثبات الإستمارة: قام فريق البحث بالتأكد من الصدق الإحصائي للمقياسين على الصى طريقة (إعادة الاختبار) حيث نم تطبيق المقياس على عينة من أعضاء مجالس الإدارة عددهم

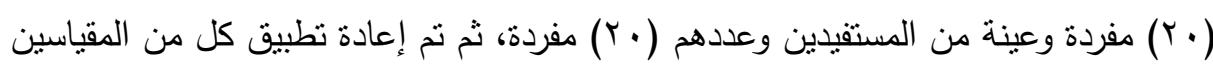


على العينة نفسها بعد مضى خمسة عشر يوماً من ناريخ النطبيق الأول، ثم تبين الصدق الإحصائى لكل من المقياسين.

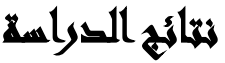

لقد تباينت إجابات المبحوثين على المقياسين وكانت النتائج ما ثبت صحته فروض الدراسة (الفرض البديل) ومنها ما ثبت عدم صحة الفرض (الفرض العدم) وقد أعطت

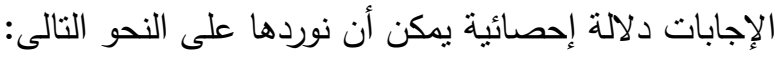

اختبار صحة فروض الدراسة: الفرض الرئيسي الأول

جدول(1): يوضح الفروق بين منوسطات أعضاء مجلس إدارة الجمعيات في كل من الريف والحضر في متغير وضوح أهداف الجمعية في حماية الحقوق البيئية للمواطنين

Independent Samples Test باستخدام

\begin{tabular}{|c|c|c|c|c|c|c|c|}
\hline الدلالة & قيمة (ت) & د. د. & الالانحرافي & المتوسطات & ن & المبحوثين & المتغير \\
\hline \multirow{2}{*}{ غير } & \multirow{2}{*}{$r T, V T r$} & וזד & $q, 1 \wedge \vee$ & $\leqslant r, 00$ & זד & الحضر & \multirow{2}{*}{ الجمعية في حماية ألهداف } \\
\hline & & $r . \tau$ & $K, 0 \leqslant V$ & $\leqslant 1,70$ & $r \cdot v$ & الريف & \\
\hline
\end{tabular}

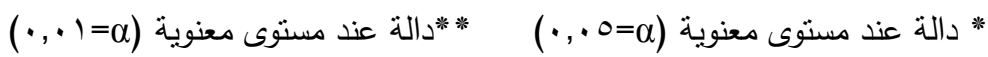

يتضح من الجدول السابق والخاص بالفروق بين متوسطات أعضاء مجلس إدارة الجمعيات في كل من الريف والحضر في متغير وضوح أهداف الجمعية في حماية الحقوق البيئية للمواطنين أنه لا توجد فروق جوهرية دالة إحصائيا بين وضوح أهداف الجمعية في حماية الحقوق البيئية للمواطنين في كل من الريف والحضر بالنسبة لأعضاء مجلس الإدارة. 
جدول (Y): يوضح الفروق بين منوسطات أعضاء مجلس إدارة الجمعيات في كل من الريف والحضر في متغير مدى وقوف المشروعات التي تقدمها الجمعية في حماية

الحقوق البيئية للمواطنين باستخدام Independent Samples Test

\begin{tabular}{|c|c|c|c|c|c|c|c|}
\hline الدلالة & قيمة (ت) & د. د & الالاعرافي & المتوسطات & ن & المبحوثين & المتغير \\
\hline \multirow{2}{*}{$\cdot, .0 *$} & \multirow{2}{*}{ גו } & I) & $11, r 01$ & $70,1 Y \leq$ & rד & الحضر & \multirow{2}{*}{ الجقوف المشروعات القدمها } \\
\hline & & $r . \tau$ & $\Lambda, Y 01$ & $\varepsilon r, I Y \varepsilon$ & $r \cdot v$ & الريف & \\
\hline
\end{tabular}

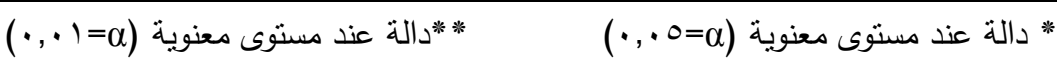

يتضح من الجدول السابق والخاص بالفروق بين متوسطات أعضاء مجلس إدارة الجمعيات في كل من الريف والحضر في متغير مدى وقوف المشروعات التي تقدها الجمعية

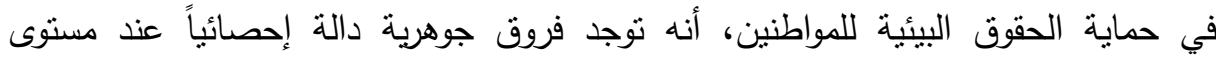

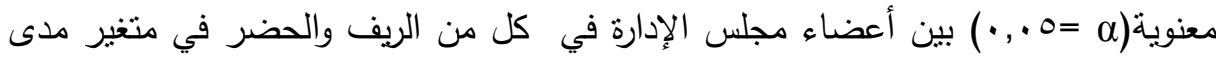

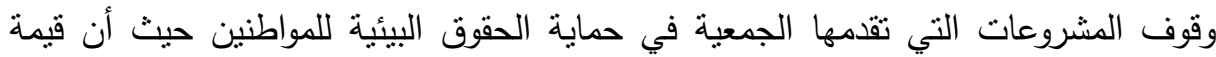

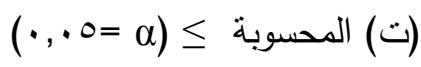

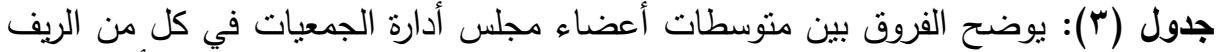

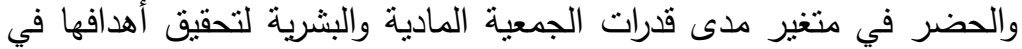

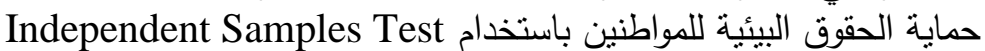

\begin{tabular}{|c|c|c|c|c|c|c|c|}
\hline الالالة & قيمة (ت) & ح.د & الانحراف & المتوسطات & ن & المبحوثين & المتغير \\
\hline \multirow{2}{*}{., $.0 *$} & \multirow{2}{*}{ ع } & ) & $\Lambda, Y \circ V$ & $0 \leqslant, Y 1$. & rצr & الحضر & \multirow{2}{*}{ قدات الجمدعية المادية } \\
\hline & & $r . \tau$ & $9, Y \circ \leqslant$ & $r, 101$ & $r \cdot v$ & الريف & \\
\hline
\end{tabular}

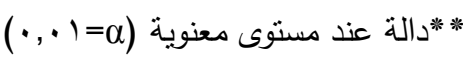

* دالة عند مستوى معنوية (م=ه •, • ) 
يتضح من الجدول السابق والخاص بالفروق بين منوسطات أعضاء مجلس إدارة الجمعيات في كل من الريف والحضر في متغير مدى قدرات الجمعية المادية والبشرية لتحقيق

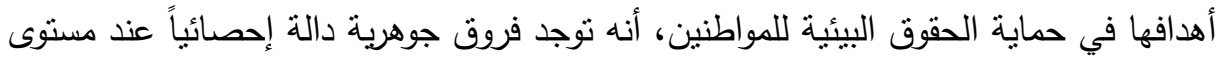

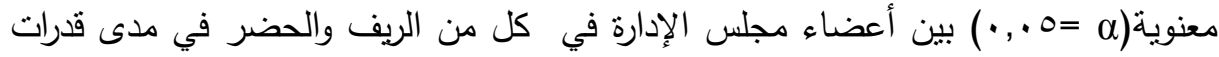
الجمعية المادية والبشرية لتحقيق أهدافها في حماية الحقوق البيئية للمواطنين حيث أن قيمة

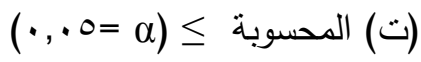

جدول (؛): يوضح الفروق بين منوسطات أعضاء مجلس إدارة الجمعيات في كل من الريف والحضر في متغير مدى تغطية الجمعية لاحتياجات المجتمع البيئية في حماية

الحقوق البيئية للمواطنين باستخدام Independent Samples Test

\begin{tabular}{|c|c|c|c|c|c|c|c|}
\hline الدلالة & قيمة (ت) & د.د & الالانحراف & المتوسطات & ن & المبحوثين & المتغير \\
\hline \multirow[b]{2}{*}{$\cdot, .0 *$} & \multirow[b]{2}{*}{ r } & ון & $M, 0 \leqslant V$ & $01, Y T \leq$ & rTt & الحضر & \multirow{2}{*}{ 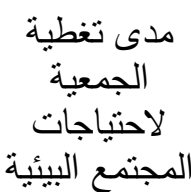 } \\
\hline & & T. & $11, r \circ \varepsilon$ & & $\Gamma \cdot v$ & الريف & \\
\hline
\end{tabular}

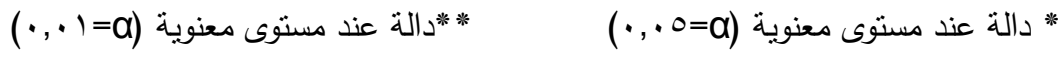

يتضح من الجدول السابق والخاص بالفروق بين متوسطات أعضاء مجلس أدارة الجمعيات

في كل من الريف والحضر في متغير مدى تغطية الجمعية لاحتياجات المجتمع البيئية في

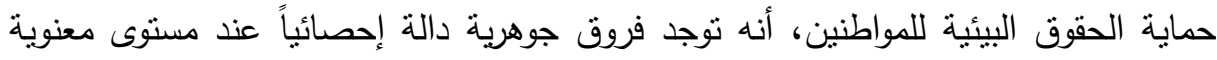

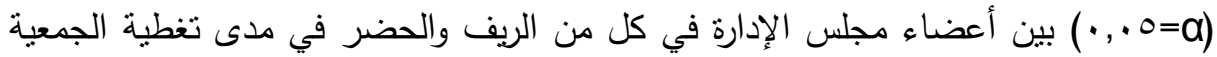
لاحتياجات المجتمع البيئية في حماية الحقوق البيئية للمواطنين حيث أن قيمة (ت)

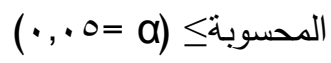

الفرض العدم (HO) "لا توجد فروق جوهرية دالة إحصائيا بين كفاءة دور الجمعيات الأهلية البيئية في حماية الحقوق البيئية للمواطنين بين الريف والحضر ". الفرض البديل (H1) "توجد فروق جوهرية دالة إحصائيا بين كفاءة دور الجمعيات الأهلية البيئية في حماية الحقوق البيئية للمواطنين بين الريف والحضر".

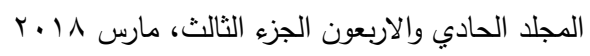


حيث إتضح قبول الفرض العدم ورفض الفرض البديل لمتغير وضوح أهداف الجمعية في حماية الحقوق البيئية للمواطنين في كل من الريف والحضر . أما بالنسبة لمتغيرات مدى وقوف المشروعات التي تقدمها الجمعية في حماية الحقوق البيئية للمواطنين في كل من الريف والحضر ، ومتغير مدى قدرات الجمعية المادية والبشرية لتحقيق أهدافها في كل من الريف والحضر ، ومتغير توجد فروق جوهرية دالة إحصائيا بين

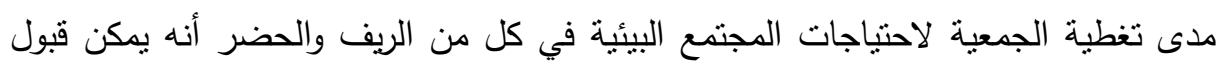

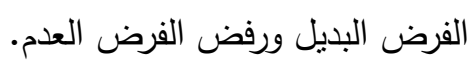
الفرض الرئيسي الثاني: جدول(ه): يوضح الفروق بين متوسطات المستقبدين في كل من الريف والحضر في متغير وضوح أهداف أنشطة ومشروعات الجمعية في حماية الحقوق البيئية للمواطنين

Independent Samples Test باستخدام

\begin{tabular}{|c|c|c|c|c|c|c|c|}
\hline الالالة & قيمة (ت) & د. & الالانحرافي & المتوسطات & ن & المبحوثين & المتغير \\
\hline \multirow{2}{*}{$\cdot, .0 \%$} & \multirow{2}{*}{ YA, TY } & $19 V$ & $\Lambda, Y \circ \leqslant$ & TT, TYA & 191 & الحضر & \multirow{2}{*}{ وضنوح أهداف } \\
\hline & & rNT & $q, \wedge \vee q$ & $\varepsilon r, Y \leq 1$ & YA & الريف & \\
\hline
\end{tabular}

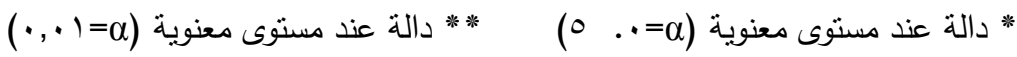

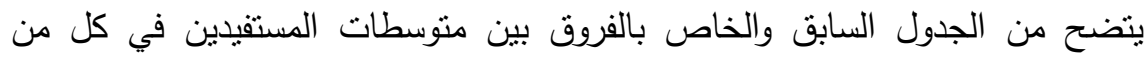

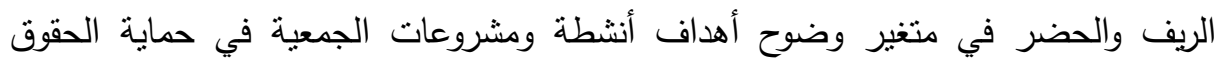

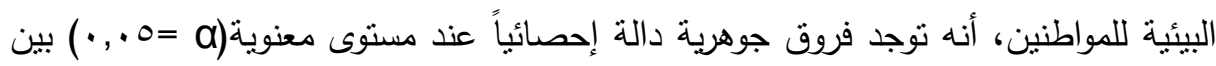
المستقيدين في كل من الريف والحضر في مدى وضوح أهداف أنشطة ومشروعات الجمعية

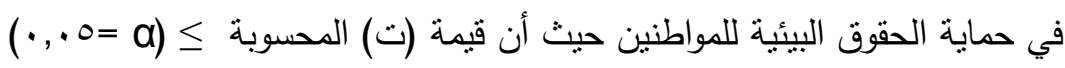


جدول (7): يوضح الفروق بين منوسطات المستقيدين في كل من الريف والحضر في متغير

الوقوف على المشروعات التي تقدما الجمعية في حماية الحقوق البيئية

Independent Samples Test للمواطنين باستخدام

\begin{tabular}{|c|c|c|c|c|c|c|c|}
\hline الدلالة & قيمة (ت) & ح.د & الانحراف & المتوسطات & ن & المبحوثين & المتغير \\
\hline \multirow{2}{*}{$\cdot, .0 *$} & \multirow{2}{*}{ TI, } & $19 \mathrm{~V}$ & $9, Y \circ \Lambda$ & $r r, q \wedge V$ & 191 & الحضر & \multirow{2}{*}{ القشدروف على الجرات التي } \\
\hline & & rAT & $11, r q \vee$ & $\Gamma \wedge, \mid \wedge \vee$ & $r \wedge \varepsilon$ & الريف & \\
\hline
\end{tabular}

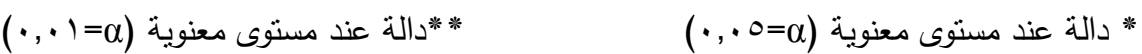

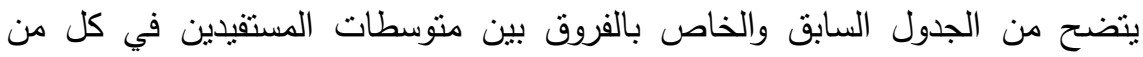
الريف والحضر في متغير الوقوف على المشروعات التي تقدمها الجمعية في حماية الحقوق

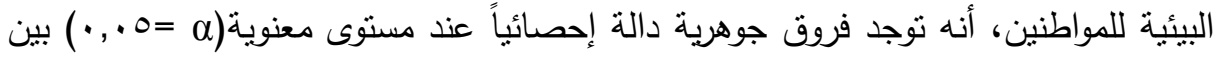
المستفيدين في كل من الريف والحضر في مدى الوقوف على المشروعات التي تقدمها

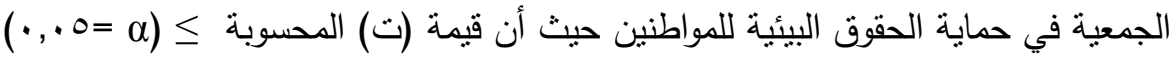
جدول (V): يوضح الفروق بين منوسطات المستفيدين في كل من الريف والحضر في متغير الوقوف على مدى تغطية الأنشطة لاحتياجات المستقيدين باستخدام

Independent Samples Test

\begin{tabular}{|c|c|c|c|c|c|c|c|}
\hline الدلالة & قيمة (ت) & د. & الانحراف & المتوسطات & ن & المبحوثين & المتغير \\
\hline \multirow{2}{*}{$\cdot, .0 *$} & \multirow{2}{*}{ r., } & $19 V$ & $1 r, 9 \Lambda$. & $\varepsilon \wedge, 9 \vee \leqslant$ & 191 & الحضر & \multirow{2}{*}{ 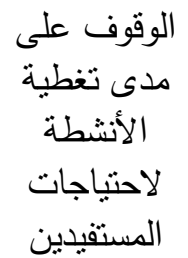 } \\
\hline & & rNT & $\wedge, Y \wedge)$ & $T, 70 \leqslant$ & r^乏 & الريف & \\
\hline
\end{tabular}


يتضح من الجدول السابق والخاص بالفروق بين متوسطات المستفيدين في كل من الريف والحضر في متغير الوقوف على مدى تغطية الأنشطة لاحتياجات المستقيدين في

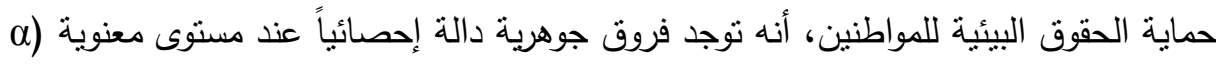
= • ., •) بين المستقيدين مجلس الإدارة في كل من الريف والحضر في مدى تغطية الأنشطة

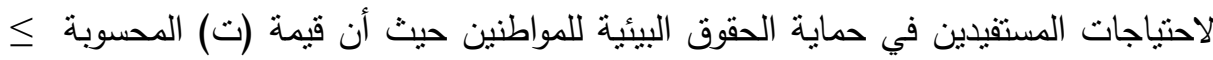

$$
(\cdot, \cdot 0=\alpha)
$$

جلول (^): يوضح الفروق بين منوسطات المستفيدين في كل من الريف والحضر في متغير الوقوف على مدى تغطية المشروعات لحاجة البيئة

\begin{tabular}{|c|c|c|c|c|c|c|c|}
\hline الدلالة & قيمة (ت) & $\tau \cdot د$ & الانحراف & المتوسطات & ن & المبحوثين & المتغير \\
\hline \multirow{2}{*}{$\cdot, .0 *$} & \multirow{2}{*}{ rq, rol } & $19 V$ & $1 r, q \wedge$. & $\varepsilon \wedge, 9 \vee \leqslant$ & 191 & الحضر & مدى تغطية على \\
\hline & & rAr & $\wedge, r \wedge)$ & T1,70 & TA乏 & الريف & لحاجة البيئية \\
\hline
\end{tabular}

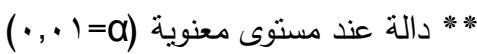

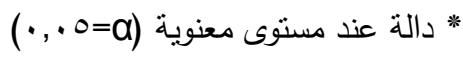

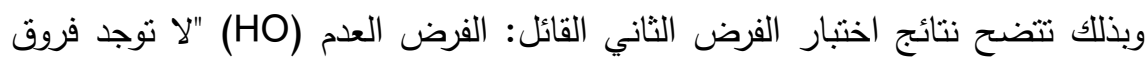
جوهرية دالة إحصائيا بين فاعلية دور الجمعيات الأهلية البيئية في حماية الحقوق البيئية

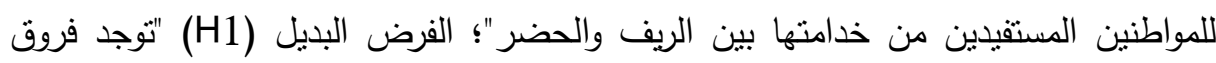
جوهرية دالة إحصائيا بين فاعلية دور الجمعيات الأهلية البيئية في حماية الحقوق البيئية للمواطنين المستقبدين من خدامتها بين الريف والحضر ".

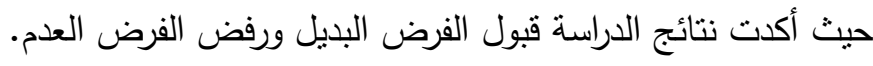




\section{توسيايت السراسها}

أولاً: القائمون على العمل بالجمعية: ضرورة إعداد برامج توعية تغطى جميع أنواع

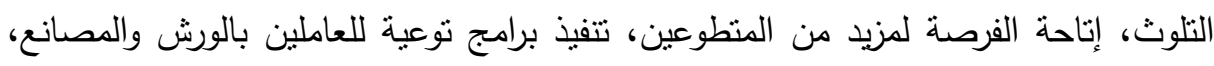

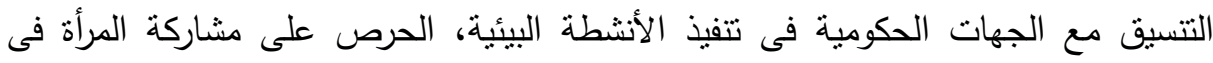
الأنشطة البيئية، الإستعانة بمتخصصين فى مجال حماية البيئة، المشاركة فى الإجتماعات

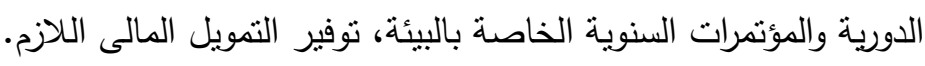
ثانياً: المستفيدون من خدمات الجمعية: ضرورة إصدار منشورات ومجلات دورية للتوعية بالبيئة، السماح للمستفيدين بالمشاركة فى الأنشطة البيئية (تخطيط، تنفيذ، متابعة)، تكثيف برامج التوعية، شمول مناهج التربية والتعليم على مادة أساسية للبيئة.

\section{المراليع}

أمانى قنديل، مؤسسة المجتمع المدنى، قياس الفاعلية ودراسة حالات القاهرة، مركز الدراسات

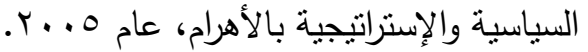

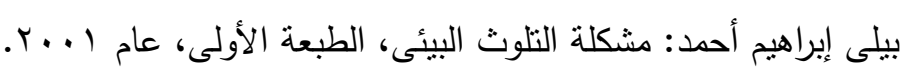

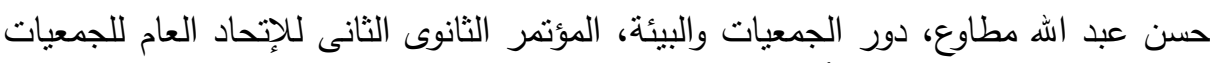

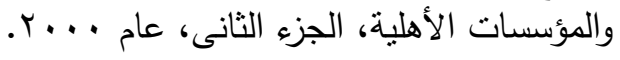

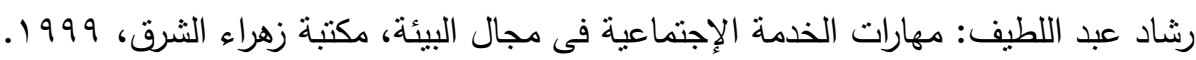
سحر حافظ: التتظيم القانونى لدور الجمعيات الأهلية فى الدفاع عن حماية البيئة، المؤنمر الإنياء

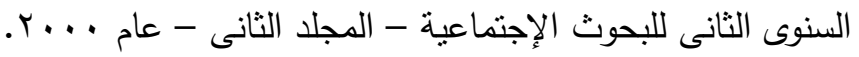

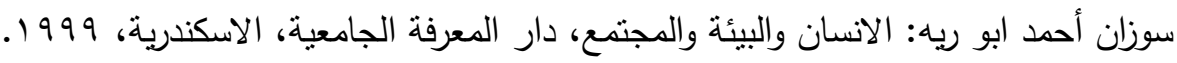

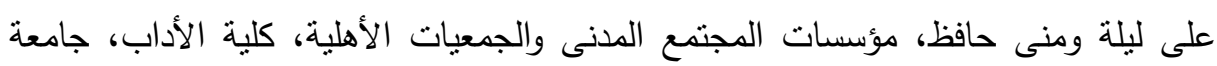
عين شمس، شركة ناسن للطباعة.

فالح سيد العجمى: دور المجتمع المدنى فى تتمية المسئولية الإجتماعية والسلوك الإيجابى الإئي نحو البيئة - دراسة إجتماعية بمدينة الكويت، معهد الدراسات والبحوث البئة البيئية،

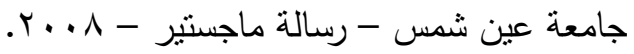

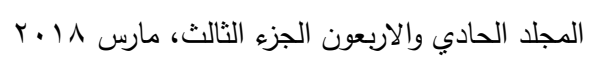




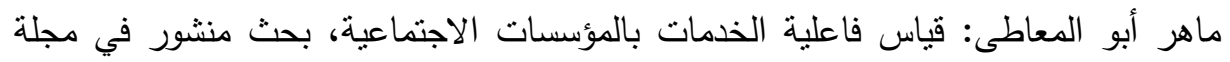
دراسات في الخدمة الاجتماعية والعلوم الإنسانية، كلية الخدمة الإناعة الإتماعية،

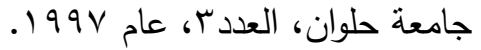

محمد محمود أحمد السيد: دور الجمعيات الأهلية فى إدارة الأزمات والكوارث البيئية، معهد

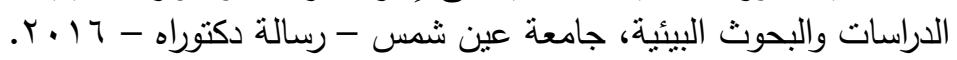

Cameron, Kim S. (1986): "Effectiveness As Paradox: Consensus and Conflict in Conceptions of Organizational Effectiveness" Management Science, vol.32,No.5.

Delbert C. Miller (1991): Hand book of Research Design and Social Measurement, London, sage Publications, Edition.

Deutch Metron \& Robert M. Karouss (1995): therories in social psychology, basic books (inc, library of congress card, no.65).

Doutch \& Krauss (1965): Theories of Social Psychology, Basic Book, N.Y.

Philippe Cullet (1995): 13 Netherlands Quarterly of Human Rights 25. 
مصطفى عوض وآخرون

\title{
A STUDY CONTAINS AN EVALUATION OF THE ROLE OF NGO IN THE ENVIRONMENTAL PROTECTION OF THE ENVIRONMENTAL RICHTS \\ OF CITIZENS - SOCIAL STUDY IN AN URPAN ENVIRONMENT AND OTHER RURAL
}

Awad, M. I. ${ }^{(1)}$; El-Sayed, T. A. ${ }^{(2)}$ and Borham, Ghadeer, E. 1) Institute of Environmental Studies and Research, Ain Shams University 2) General Union of $\mathrm{NGO}_{\mathrm{S}}$

\begin{abstract}
The study aims to determine the impact of NGOs in educating citizens in preserving the environment in the rural and urban society. The study population of Dakahlia (a group of environmental NGOs) reached 72 associations, 37 of which are urban and 35 rural. And the number of 482 beneficiaries in these associations.

The study uses more than one approach, the most important of which is the social survey in both the comprehensive and the sample. Two measures were designed, the first is to measure the efficiency of the workmen of the society, and the second is to measure the effectiveness of the beneficiaries of the services of these associations.

The study reached a set of results that can be summarized as: The results of the first hypothesis test: "No significant differences are statistically significant between the efficiency of the role of environmental NGOs in protecting the environmental rights of citizens between rural and urban", while the alternative hypothesis H1 ("There are differences A significant statistical function between the efficiency of the role of environmental NGOs in protecting the environmental rights of citizens between rural and urban. "The acceptance of the null hypothesis and the rejection of the alternative hypothesis of the clarity
\end{abstract}

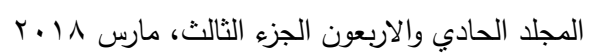




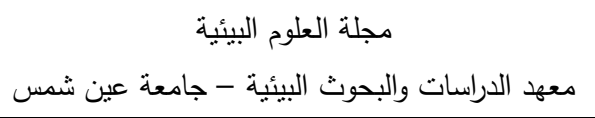

of the objectives of the association in protecting the environmental rights of citizens in both rural and urban areas became apparent.

Thus, the results of the second hypothesis test (null hypothesis HO) show that there are no statistically significant differences between the effectiveness of the role of environmental NGOs in protecting the environmental rights of citizens benefiting from their rural / urban services, while alternative hypothesis H1 ("There are significant differences statistically significant Between the effectiveness of the role of environmental NGOs in protecting the environmental rights of citizens benefiting from their services between rural and urban. "Where the results of the study confirmed acceptance of the alternative hypothesis and rejection of nullity.

The study reached a number of recommendations, The need to prepare awareness programs covering all types of pollution, to allow more volunteers, to ensure the participation of women in environmental activities, the use of specialists in the field of environmental protection, the inclusion of education curricula on the basic material for the environment. 